\title{
The Normalization of the "Active-Sedentary" Lifestyle in Spanish Youth
}

\author{
David Moscoso-Sánchez¹, Raúl Sánchez-García², Maria Martín-Rodríguez³, \\ Natalia Pedrajas-Sanz ${ }^{3}$ \\ ${ }^{1}$ Sociology Department, Pablo de Olavide, Sevilla, Spain \\ ${ }^{2}$ Fundamentals of Motricity and Sports Training Department, Universidad Europea de Madrid, Madrid, Spain \\ ${ }^{3}$ Faculty of Physical Activity and Sport Sciences, Polytechnic University of Madrid, Madrid, Spain \\ Email: dmoscoso@upo.es
}

Received 8 June 2014; revised 10 July 2014l; accepted 18 July 2014

Copyright (C) 2014 by authors and Scientific Research Publishing Inc.

This work is licensed under the Creative Commons Attribution International License (CC BY).

http://creativecommons.org/licenses/by/4.0/

cc) (i) Open Access

\begin{abstract}
Sedentarism has become one of the major concerns of our times. Nowadays people spend most of the time sitting down and moving by mechanical means instead of exercising themselves. Younger generations do only a little more sport today than their counterparts did a decade ago. In other words, sedentary habits have become common in our society, especially among the young. What cultural mechanisms have contributed to this? What are the consequences of a sedentary lifestyle for our health and well-being? These are the questions we have posed in this study. We conducted qualitative research among Spanish young people, and the results have provided important clues to help us understand better how "active sedentarism" has become the norm among young people.
\end{abstract}

\section{Keywords}

Lifestyle, Active Sedentarism, Physical Activity and Sport, Young People

\section{Introduction}

Professionals in the health sciences have demonstrated through epidemiological and longitudinal studies the importance of physical activity and sport in maintaining our health and quality of life (Raphael, 2006; Blair, Kohl, Gordon, \& Paffenbarger, 1992). Sport and physical exercise produce physical, biological, psychological and social benefits and are important at both a therapeutic and preventive level.

Despite the recognized multiple benefits of sport, only 4 out of 10 Spanish citizens practice sports. Moreover, just 7 out of 10 walk every day, and only 4 out of 10 have daily occupations involving some type of physical exertion (work, study, housework, etc.) (Moscoso \& Moyano, 2009). In light of these data, it is clear that many 
citizens do not enjoy the benefits associated with physical activity and sport (PAS). On the contrary, they suffer from the consequences of inactivity.

This is a very common situation among younger generations in western countries, as a sedentary lifestyle has become established in this population group. Young people are increasingly consuming high-calorie foods and toxic substances; they are inactive, and most of their leisure activities are passive. According to the Observatory of Sustainability in Spain, the rate of obesity among the Spanish population under 24 years of age is the highest in Europe: approximately 4 out of 10 children and youth suffer from obesity or overweight. This problem, more acute in Spain than in other countries in Europe, explains the increase in the early onset of diseases caused by sedentary lifestyles.

Our research is based on the hypothesis that in order to reverse this situation, it is necessary to analyze the effects of contemporary cultural trends — especially those associated with leisure-on the abandonment of physical activity and sports (PAS). The analysis of such cultural trends allows us to detect the factors that lead to inactivity among young people today.

Our approach also requires a focus on socialization processes and institutions. Some authors have demonstrated the influence of socialization at an early age on participation in physical activity and sports (García, 2001). The results of our prior research (Moscoso \& Moyano, 2009) have also revealed that the practice of sport among parents is decisive for the practice of sport among children, although other institutions such as schools also play a role. Our previous studies also indicate that the practice of sport in childhood and youth is decisive in determining whether individuals continue to do so later in life (Table 1).

Thus, we argue that in order to address the sedentary habits and behaviors of young people, it is necessary to establish structural sport policies in the primary institutions of socialization (family, schools, and communication media). These are the institutions with the greatest capacity to transform social structures and dynamics, and therefore habits related to PAS. This way of focusing sports policies-until now anchored in the fossilized structure of sports federations, at least in Spain —would serve to counter the trend toward sedentarism among young people, and therefore guarantee a better health and well-being for this part of the population.

\section{Method}

To test our hypothesis, we have carried out a qualitative study based on focus groups. Our aim has been to explore the values, perceptions, attitudes and behaviors of young people regarding their lifestyles, and specifically physical activity and sport. We used this method so that participants could express themselves openly, with the least possible involvement of the researcher.

Regarding sample design, we have opted for strategic criteria. The research has focused exclusively on young adults, considering this intensive strategy the most effective. The total amount of participants was 46 (21 men and 25 women). Based on our experience in previous studies (Moscoso \& Moyano, 2009), we have grouped young people into two segments: those from 18 to 24 years of age and those from 25 to 34 years of age. We agree with Alonso and Conde (1994: p. 123) that "there is no single unified population of young adults; instead, there are various groups of young adults based on their different social situations". In this regard, we believe that

Table 1. Practice sport in Spain: relationship between the present and the past.

\begin{tabular}{cccc}
\hline \multirow{2}{*}{ Practiced sport in past stages of life } & \multicolumn{2}{c}{ Practice sport in the present stage of life } \\
\cline { 3 - 4 } As a child & Yes & Yes & No \\
\hline \multirow{2}{*}{ As a teenager } & No & 79.0 & 48.5 \\
& Yes & 20.7 & 40.9 \\
No & 73.5 & 58.3 & 22.1 \\
\hline
\end{tabular}

Source: Moscoso and Moyano (2009, p: 179). 
these two age groups represent the two predominant phases among Spanish young adults at this time, while also assuming that the age bracket of "youth" has been extended to somewhat older ages at present.

Our sample design also includes socio-demographic and socio-economic variables such as region of residency, age, sex and education level, as well as participation/non-participation in physical activity and sport (Table 2).

In this way, the social heterogeneity of Spanish young people is represented in regard to the structure of the practice of PAS. In addition, the territorial variable is important as there are still significant socio-economic differences between regions in Spain which influence the unequal structure in the practice of sport (Martínez \& Navarro, 1992). With this in mind, in order to carry out our field work we selected two highly developed regions (Catalonia and Madrid), one with a lower level of development (Andalusia) and one with an intermediate level (Castilla-León). However, logically, despite taking regional inequalities into account in our sample design, the limitations of the results of a qualitative study of this type do not permit us to make judgments based on these differences.

There were seven different focus groups in different Spanish cities. To select the participants, we relied on the support of public administrations and organizations of different types (educational, scientific and institutional) and on a full-time researcher in charge of organization. The dynamic of the focus groups was designed to be open. The script addressed the following points: lifestyle, free time, physical activity and sport, health and quality of life.

\section{Results}

Lifestyles: free time, social relations and digital leisure

Our research shows that young people's lifestyles are very influenced by their free time. It occupies a central part of their lives, or at least serves as a frame of reference from a symbolic perspective. What is consistently highlighted is the high and varied number of activities young people do in their daily lives (study, friends, dancing, music, languages, events, travel, Internet, etc.). Identification with this lifestyle is demonstrated in the value placed on being an "active person".

Mine [lifestyle] is totally active. Since I was little, I have signed up for everything, everything I liked, I have tried everything [Focus Group 6: man, practices sport, 34 years old].

I consider myself to be quite active, but I think it's because I don't know how to stop and do nothing... it's in part in response to the model of life imposed on us, since we were little... I think it's burned into me that I have to be productive, that I have to be busy [Focus Group 4: woman, practices sport, 34 years old].

Yes, because when we were little they instilled in us the idea that after school you have to take English classes or karate or music or dance classes. You always have to be doing something [Focus Group 4: woman, practices sport, 32 years old].

The discourse of young people also reveals another characteristic that is a hallmark of their identities and around which their lifestyles revolve: "social relations". All of them like to spend time with their peers when they are not busy with the main tasks of their daily lives (their studies and/or work). But when speaking about social relations, what stands out is that a good deal of their discourse refers to social networks (on the Internet), as if social relations and social networks on the Internet were the same thing-identifying with what is unders

\begin{tabular}{ccccc}
\multicolumn{2}{l}{ Table 2. Participants in focus group. } \\
\hline $\mathbf{N}^{\circ}$. Focus Group & Region & $\mathbf{N}^{\circ}$. Participants & Sex \& Age & Practice Sport? \\
\hline FG-1 & Andalusia & 8 & $18-24$, man and woman & No \\
FG-2 & Andalusia & 7 & $25-34$, man & Yes \\
FG-3 & Madrid & 6 & $25-34$, woman & Yes \\
FG-4 & Madrid & 7 & $18-24$, man & Yes \\
FG-5 & Castilla-León & 5 & $18-24$, woman & Mixed \\
FG-6 & Madrid & 6 & $25-34$, man and woman & No \\
\hline
\end{tabular}

Note: Study Ref. 007/UPB10/12. 
tood as a digital lifestyle.

I use everything. I'm on Tuenti, Facebook, Twitter and then also the Student Council Twitter, which I am in charge of. And, for example, I maybe have a use for each one. And I also use Wordreader, which is how you get on a blog... I'm also hooked on Wassap and Gmail lists; I have 12... [Focus Group 1: man, does not practice sport, 21 years old].

However, there are also very heterogeneous situations. Analysis of the discourse in the groups reveals that the daily life projects of young people are sociologically marked by their living conditions. These, in turn, depend on the level of economic and residential autonomy they have at this stage of their lives (if they are dependent on family resources or not, and if they live in the family home or have emancipated), and the main occupation in their lives (employment, study, being unemployed, etc.).

\subsection{Active or Sedentary?}

We have already referred to the concept of the active individual to allude to the social identity of young people. Translating this concept to the area of lifestyle, its meaning is converted to the notion of being "multifaceted" or "versatile", something that we understand to be different - to a certain degree and in form-from what is understood to be a "healthy lifestyle". In effect, our research has shown that there is confusion among young adults between an active life as a way of expressing one's "attitude toward life" and being active through doing PAS, that is, as part of a "healthy lifestyle". In terms of its formal definition, there are young people who understand that this relationship between an active life and a healthy lifestyle is produced by participating in PAS. However, the majority of young people-especially in the younger of our two age groups-think they lead active lives because of their attitude toward life and the number of activities they do every day, and therefore, the idea of an active life is unrelated to leading a healthy lifestyle.

I think I have an active life... Maybe I'm not the most active person in the world, but I like to be outside all the time. If I'm not outside, I am working; if I am not working, I am doing a million things... I can't stay still [Focus Group 1: woman, does not practice sport, 18 years old].

We will start with the first group of young people, those who identify themselves as active persons because they do PAS; this group is represented by those who responded that they practice sport. Young people who do sport have energy and need physical activity, action or movement in their daily lives. These young people say that sport forms part of their daily habits; in addition, they see it as a fundamental part of leisure. They also think that being active is physically, psychologically and socially positive. They understand that doing PAS, and therefore having an active life (understood as "physically active"), helps them to maintain an active attitude in other areas of their lives, assuming physical movement to be part of their overall well-being.

Regarding the second group of young people (those who do not do PAS), we might assume that they would consider themselves to be sedentary. However, surprisingly they all consider themselves to lead active lives. There are two reasons for this: firstly, because of the numerous activities they do throughout the day —although these activities do not involve any physical activity, and secondly because they accept the popular cultural conception of being "active" as an attitude toward life. These young people describe themselves in the following terms: "I am very restless"; "I can't stop"; “I can't stay still" or "I can't sit around doing nothing”. Hence, being physically sedentary, but simultaneously socially and intellectually active, shapes their social identity as "active selves".

\subsection{Sport, Physical Activity, Health and Quality of Life}

Young people-whether or not they do PAS—understand sport to be an activity practiced to promote health, entertainment and individual well-being, and not for the sporting performance in itself. In this way, the traditional conception of organized and competitive sport seems to have been replaced with an alternative idea of sport. In Spain today, young people share a vision which is critical of high performance and spectator sports (football in particular). The origin of the criticism is that these kinds of sport saturate the news media and do not allow room for a distinct vision of sporting activity. In addition, high performance and spectator sports pervert the idea of grassroots sports—-the type of sport that young people advocate-by having a negative social, psychological and physiological impact.

I like football but I am tired of putting on sports and only hearing Cristiano Ronaldo, Messi, Cristiano Ronaldo, Messi. Look, you end up saying, ok, it’s enough already! [Focus Group 5: woman, practices sport, 18 
years old].

Barça, Madrid, football and that's it, but at the level of super-athletes... I see it more as information for us; for normal people, grassroots sports, there isn't anything [Focus Group 7: woman, does not practice sport, 25 years old].

Regarding the practice of sport, there are two types of discourse among young people. Firstly, there are young people that keep on practicing sport and, in addition, reinventing their practice. Secondly, there are those who refer to sport because they did sport in the past but no longer do so, in other words, they have abandoned their practice. Those who continue to do sport understand it as something important in their lives, a reference in their free time that contributes in a positive way to their physical, psychological and social well-being. For them, sport is something that marks their lives ("it is a way of life"; "it's a necessity"; "it's a foundation"; "it helps me in living my daily life").

Regarding the group that is physically inactive now but was active in the past, as it is difficult to understand why someone decides to quit doing sport, we decided to reverse the question: why do some young people who begin doing sport when younger continue their practice as they get older? The discourses emerging from this study offer us two possible answers. The first is related to the positive influence of different agents of socialization in childhood-especially the family and the education system. The second directly links the maintenance of sports practice during youth and later in adulthood to certain psychological benefits (relaxation, mental health, being in shape, improved social relations, self-improvement, etc.).

The first place where you get models for doing something is in the family... In my case, my parents are in a sports club, and I was always doing sports, every day, and that's why I do them now [...] Because I like it, I feel good, it's good for your health and for my mind, and socially [Focus Group 4: woman, practices sport, 34 years old].

Well, for me, physical activity is totally related to having fun. There is nothing else I can connect it to because if it isn't something that's fun, it's not worth it for me [Focus Group 2: man, practices sport, 34 years old].

In the case of young people who do not do PAS, they understand the benefits of practicing sport; however, they still think of themselves as being in good health. The question as to why they do not practice sport has many answers related to various factors ranging from lacking motivation to do so, to not having been socialized to participate in sporting culture. We should not forget more personal reasons such as lack of enjoyment or motor skills necessary for practice. We also found in the discourses certain psychological barriers related to body complexes, or others that were more practical in nature, such as being tired or not having time. In the majority of cases the latter were associated to the multiple activities (responsibilities or pleasure) that these young people carry out on a daily basis, and which therefore have more to do with personal choices than with social obstacles.

Me, sports, if I'm not a few kilos overweight, I don't do any... I also don't like doing sports alone. If no one can come with me, for example, to go running, I'm not going to do it alone... [Focus Group 1: woman, does not practice sport, 19 years old].

Well, I don't feel like I really need to do sports, and it doesn't seem useful to spend my time that way. There's not much time in the day, and I prefer to spend it on things I like or that are interesting to me [Focus Group 1: man, does not practice sport, 24 years old].

If you aren't good at it, it makes you not want to continue, and then you do it less, and then start to give it up and the more you don't do it, you get worse at it, and well, finally you just do other things [Focus Group 1: man, does not practice sport, 21 years old].

In addition, we found that the manner in which more physically active young people face life can be different from the way inactive young people do. The latter, for example, tend to share a relatively pessimistic view of life. In contrast, while difficulties at this stage of life (access to the labor market, financial autonomy, independence from family, etc.) may have a negative influence on their perception of reality, young people who are more physically active face daily life in a more positive manner.

I think that people who don't do any sport complain more about life [Focus Group, man, practices sport, 34 years old]

[...] well, you're a lot more relaxed in certain moments, so, if you have a lot of stress, you do a little exercise and it relaxes you, helps you... I mean there are days when you are just stressed out... with me I'm out on the skateboard a lot, you skate just fifteen minutes and later go home, take a shower, and you feel different [...] There is also mental health... There are a lot of people, it happens to me that, usually, my mood changes after doing sports [FG-3, man, practices sport, 21 years old]. 
Our analysis confirms that there are major differences between young people who do PAS and those who do not. PAS has a decisive weight in young people's lifestyles (defining them as active or sedentary) and, as a result, has an impact on their health and perceived well-being. Doing or not doing PAS not only affects their subjective well-being, but also the level and type of activities young people do. In their own opinion, sedentary individuals have less energy, worse moods and show less initiative and willingness to carry out physical activities ("Doing sports makes you feel stronger and you feel better, and so you have a greater desire to do more things"). This can be seen in Figure 1, where the two opposing lifestyles identified among Spanish young people are differentiated: the healthy lifestyle (active) and the sedentary lifestyle (active sedentarism).

\section{Discussion}

As the research has shown, the use of free time symbolically defines young people's lifestyles, which are characterized by the numerous and varied sedentary activities they carry out in their daily lives. Such a situation limits the possibilities for doing PAS given that the supply of free time activities is very competitive and varied. In this regard, among Spanish young people, digital leisure is the dominant use of free time and form of cultural expression. This is due to three factors: firstly, digital leisure has become essential in social relationships among young people, secondly, the use of ICTs has become a normal part of life in Spanish society, and lastly, digital leisure as a practice fits well with the sedentary lifestyles of young people, and in particular, their use of free time.

Despite this, the lifestyles of young people are heterogeneous and dependent on their socio-economic situations and socio-demographic characteristics. We have not found differences based on participants' sex or region of residence; trends in lifestyles seem to be shared generationally rather than geographically. But we do find differences based on age: those of a younger age are much more inactive. As it has been already pointed out, the heterogeneity of discourses about different lifestyles depends primarily on socioeconomic (education) and sociodemographic (age and sex) variables. Nevertheless, it is also determined by the diversity of motivations (extrinsic and intrinsic) which are related to the practice of physical activities and sports. In any case, the results of this study reveal very general tendencies, and further development of our research would permit us to examine these relationships more deeply.

Regarding PAS, the study has demonstrated significant differences between those who have a lifestyle marked by physical activity and those who do not. Those who do PAS in their free time and as part of their lifestyle, in general reject the dominant materialist and consumerist values of modernity, and in particular the current values that prevail in the area of sport. On the other hand, those who do not do PAS, while they consider themselves to be active because of all the activities they do, are in reality sedentary ("active sedentarism"); they do not fit the definition of an active lifestyle conceived from the standpoint of physical activity.

We can discern that what marks the identity of social beings culturally today does not entail work involving physical labor, but is instead related to multiple educational, work and entertainment activities that are typically sedentary. It seems that the principal group defined by these kinds of leisure and free time activities lacks basic notions of what constitutes healthy habits, thus leading to the early onset of physical and mental health problems. The main issue is that inactivity has become the norm and finds social approval in this population. This has a perverse effect, since the cycle of inactivity, as shown in Figure 2, cannot be overcome without breaking the barrier of the sedentary lifestyle. In effect, a sedentary lifestyle has worrying costs, both in terms of individual health and well-being, and in social and economic terms for the healthcare system and society.

\section{Conclusion}

This study identifies a worrying trend among Spanish youth in relation to PAS: "active sedentarism". With this definition we coin a new term to refer to a widespread phenomenon among young generations. In order to foster healthy lifestyles linked to PAS in young people, we must take into account the relevance of socialization processes. Our research has shown the importance of socialization agents in shaping the leisure activities and lifestyles of young people. As a result, we think that for PAS to become a priority for young people in their free time, mechanisms to socialize individuals into adopting sporting habits at a very young age must be strengthened in the sport and education system, as well as in the family. This should be considered an essential and beneficial practice for our health, social relations and enjoyment, as we know that these are central elements in the lives of young people who do PAS. 


\section{ACTIVE LIFE}

Physical activity and sport

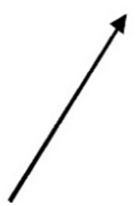

Greater psychologicalphysical capacity More energy

Better physical health

Better self-perception

Better attitude toward life

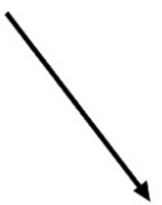

Overall well-being

Physical benefits

Physical-social benefits

\section{ACTIVE SEDENTARY LIFE}

Inactive physically

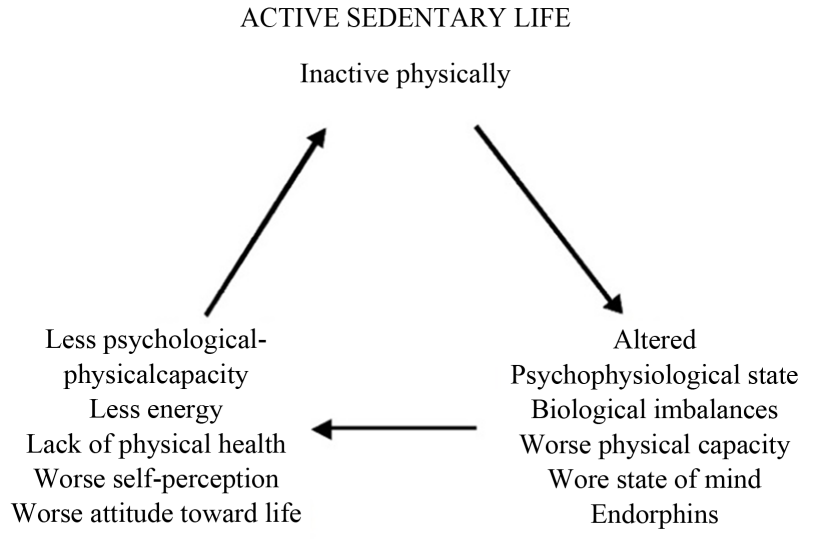

Figure 1. Active lifestyles (healthy) and inactive lifestyles (sedentary).

\section{CYCLE OF INACTIVITY}

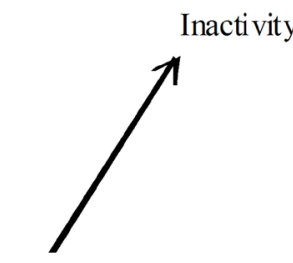

Deficit of movement

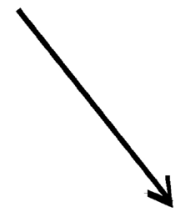

Osteo-muscular feeling of illnesses

\section{CYCLE OF ACTIVITY}

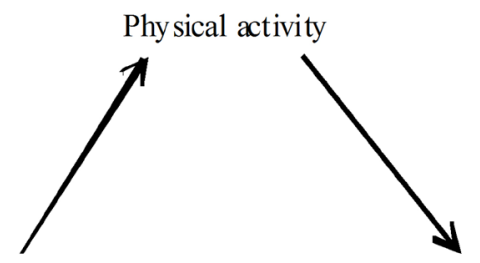

Well-being
Generation of endorphins

\section{Figure 2. Cycles of inactivity and activity, according to one of the experts.}

As a final remark we should not neglect that active sedentarism is a phenomenon which goes beyond the case we have studied in Spain, and because of its importance, it would be interesting to repeat this study in other countries in order to see if this is a global trend or if it is limited to certain regions.

\section{Funding}

This article is the result of study funded by the Higher Sports Council (CSD), Government of Spain (Ref. 007/UPB10/12)

\section{References}

Alonso, L. \& Conde, F. (1994). History Consumption Spain. An Approach to Its Origins and Early Development [Historia del consumo en España: Una aproximación a sus orígenes y su primer desarrollo]. Madrid: Debate.

Blair, S., Kohl, H., Gordon, N., \& Paffenbarger, R. (1992). How Much Physical Activity Is Good for Health? Annual Review of Public Health, 13, 99-126. http://dx.doi.org/10.1146/annurev.pu.13.050192.000531

García, M. (2001). Los españoles y el deporte: Prácticas y comportamientos en la última década del siglo XX. Madrid: Consejo Superior de Deportes.

Martínez, J., \& Navarro, C. (1992). Sport, Society and Territory. The Cases of the Regions in Spain [Deporte, sociedad y territorio. Los casos de las comunidades autónomas en España]. In K. Fasting (ed.), Abstract Book of Scientific Olimpic Conference 92 (424-429) [Actas del Congreso Científico Olímpico 92]. Málaga: Instituto Andaluz del Deporte.

Moscoso, D., \& Moyano, E. (2009). Sport, Health and Quality of Life. Barcelona: The "la Caixa” Foundation.

Raphael, D. (2006). Social Determinants of Health: Present Status, Un-Answered Questions, and Futures Directions. International Journal of Health Services, 36, 651-67. http://dx.doi.org/10.2190/3MW4-1EK3-DGRQ-2CRF 
Scientific Research Publishing (SCIRP) is one of the largest Open Access journal publishers. It is currently publishing more than 200 open access, online, peer-reviewed journals covering a wide range of academic disciplines. SCIRP serves the worldwide academic communities and contributes to the progress and application of science with its publication.

Other selected journals from SCIRP are listed as below. Submit your manuscript to us via either submit@scirp.org or Online Submission Portal.
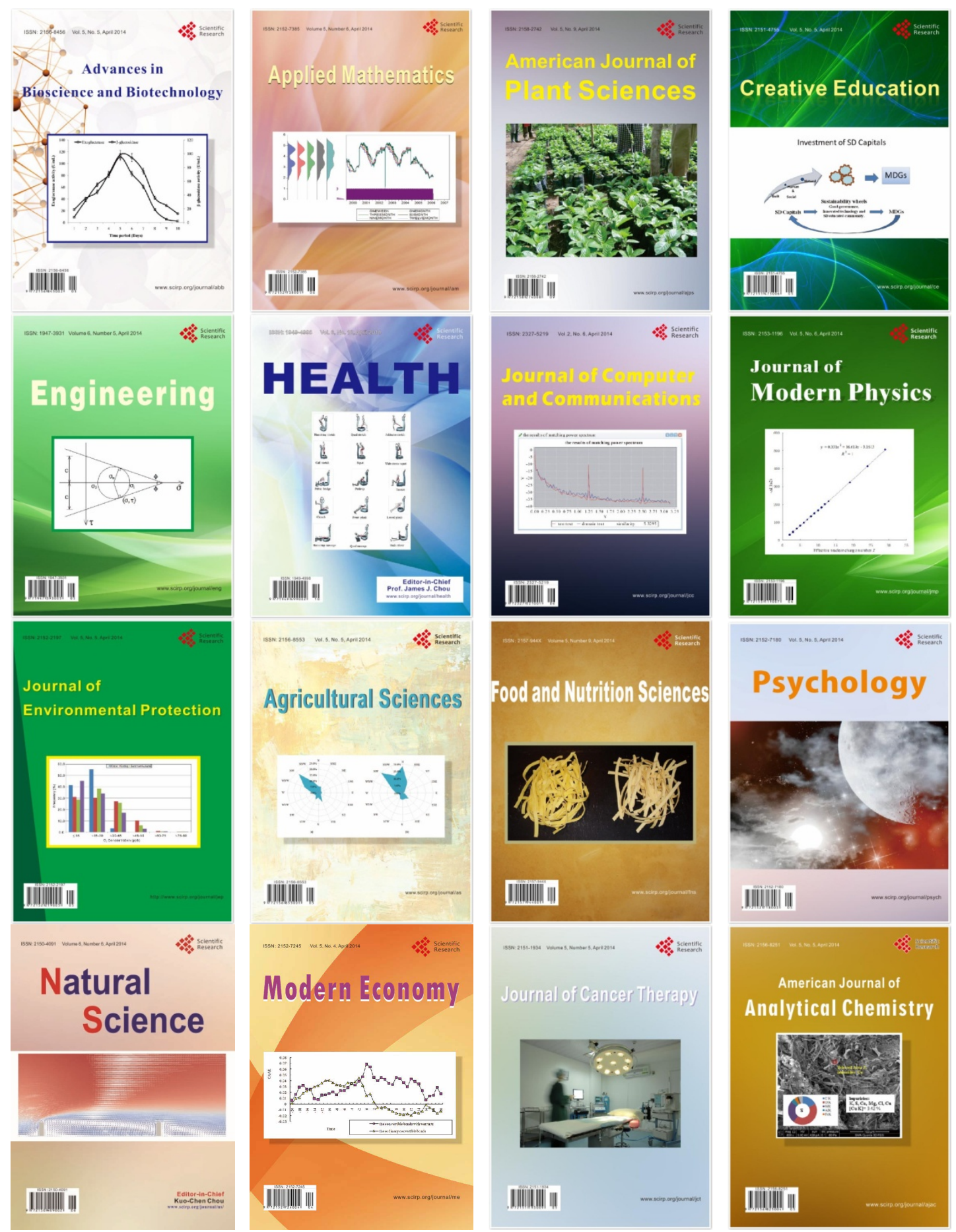